\title{
The synergistic effects of DNA-damaging drugs cisplatin and etoposide with a histone deacetylase inhibitor valproate in high-risk neuroblastoma cells
}

\author{
TOMAS GROH $^{1,2}$, JAN HRABETA $^{2}$, MOHAMMED ASHRAF KHALIL ${ }^{2}$, \\ HELENA DOKTOROVA $^{2}$, TOMAS ECKSCHLAGER ${ }^{2}$ and MARIE STIBOROVA ${ }^{1}$ \\ ${ }^{1}$ Department of Biochemistry, Faculty of Science, Charles University, 12840 Prague 2; \\ ${ }^{2}$ Department of Pediatric Hematology and Oncology, 2nd Medical Faculty, \\ Charles University and University Hospital Motol, 15006 Prague 5, Czech Republic
}

Received March 9, 2015; Accepted April 14, 2015

DOI: 10.3892/ijo.2015.2996

\begin{abstract}
High-risk neuroblastoma remains one of the most important therapeutic challenges for pediatric oncologists. New agents or regimens are urgently needed to improve the treatment outcome of this fatal tumor. We examined the effect of histone deacetylase (HDAC) inhibitors in a combination with other chemotherapeutics on a high-risk neuroblastoma UKF-NB-4 cell line. Treatment of UKF-NB-4 cells with DNA-damaging chemotherapeutics cisplatin or etoposide combined with the HDAC inhibitor valproate (VPA) resulted in the synergistic antitumor effect. This was associated with caspase-3-dependent induction of apoptosis. Another HDAC inhibitor trichostatin A and a derivative of VPA that does not exhibit HDAC inhibitory activity, valpromide, lacked this effect. The synergism was only induced when VPA was combined with cytostatics targeted to cellular DNA; VPA does not potentiate the cytotoxicity of the anticancer drug vincristine that acts by a mechanism different from that of DNA damage. The VPA-mediated sensitization of UKF-NB-4 cells to cisplatin or etoposide was dependent on the sequence of drug administration; the potentiating effect was only produced either by simultaneous treatment with these drugs or when the cells were pretreated with cisplatin or etoposide before their exposure to VPA. The synergistic effects of VPA with cisplatin or etoposide were associated with changes in the acetylation status of histones $\mathrm{H} 3$ and $\mathrm{H} 4$. The results of this study provide a rationale for clinical evaluation of the combination of VPA and cisplatin or etoposide for treating children suffering from high-risk neuroblastoma.
\end{abstract}

Correspondence to: Professor Marie Stiborova, Department of Biochemistry, Faculty of Science, Charles University, Albertov 2030, 12840 Prague 2, Czech Republic

E-mail: stiborov@natur.cuni.cz

Key words: neuroblastoma, cisplatin, etoposide, valproate, acetylation of histones, apoptosis

\section{Introduction}

Neuroblastoma is the most common extracranial solid tumor of childhood. These tumors are biologically heterogeneous, with cell populations differing in their genetic programs, maturation stage and malignant potential. Neuroblastoma cells seem to have the capacity to differentiate spontaneously in vivo and in vitro, they may regress spontaneously in infants, mature to benign ganglioneuroma, or grow relentlessly and be rapidly fatal $(1,2)$. This heterogeneity could affect treatment outcome, in particular the response to apoptosis induced by chemotherapy. Even though a great progress has recently been made in pediatric oncology, all accessible approaches have still failed to cure the high-risk neuroblastoma (3). Indeed, little improvement in therapeutic options has been made in the last decade, requiring the development of new therapies.

The chromatin structure plays a role in the origin of neuroblastomas (4). Dynamic formation of chromatin leads not only to transcription of different genes but DNA is also more accessible for DNA-targeted chemotherapeutics. Several genes are described as epigenetically influenced in neuroblastoma cells (5). DNA hypermethylation and gene silencing is usually associated with the abundance of deacetylated histones, the other essential actors of epigenetic mechanisms (6). Therefore, histones are key players in epigenetics, and their status dictates accessibility of transcription factors that regulates DNA transcription (7).

The core histones $\mathrm{H} 3, \mathrm{H} 4, \mathrm{H} 2 \mathrm{~A}$ and $\mathrm{H} 2 \mathrm{~B}$ around which $147 \mathrm{bp}$ of DNA are wrapped and predominantly globular except for their $N$-terminal tails, which are unstructured (8). There are at least eight distinct types of modifications. One of the most important histone modifications is acetylation of lysine residues, which regulates various cell processes such as transcription, repair, replication and condensation of DNA (8). Histone acetylation is regulated by the equilibrium of two groups of enzymes: histone acetyltransferases (HATs) and histone deacetylases (HDACs) (6). HDACs also play an important role in post-transcriptional modifications in a variety of non-histone proteins such as transcription factors, chaperones or signaling molecules (9). 
In the last decades, numerous compounds that act as inhibitors of HDACs have been studied as potential anticancer drugs. Various HDAC inhibitors initiate cancer cell death by different processes, depending on the cell types, because they have a variety of cellular targets. These mechanisms include changed gene expression and alterations of histone and also of non-histone proteins by epigenetic and post-translational modifications (10). The results found in several studies testing the efficiency of HDAC inhibitors alone or in a combination with chemotherapy and/or radiotherapy demonstrated that HDAC inhibitors can have additive and/or even synergistic effects when used with some cytotoxic reagents or ionizing radiation (11-14). Even though various molecular mechanisms were shown to be responsible for the observed higher sensitivity of tumor cells towards therapeutic agents elicited by HDAC inhibitors (reviewed in refs. 10,15-22), these mechanisms need to be further investigated.

In this study, we investigated the combined effects of two HDAC inhibitors, valproate (VPA) and trichostatin A (TSA), with two DNA-damaging drugs, cisplatin and etoposide, on a human high-risk neuroblastoma UKF-NB-4 cell line. Cytotoxicity of cisplatin is based on cisplatin-induced DNA adducts that include protein-DNA cross-links, DNA monoadducts, and interstrand or intrastrand cross-links (23), as well as on the generation of reactive oxygen species (ROS) in cells $(24,25)$. Etoposide acts as a DNA intercalator and an inhibitor of topoisomerase II activity generating the single- and doublestrand DNA breaks (26-28). VPA, an inhibitor of class I and IIA HDACs (29), is used as an anti-epileptic drug, but it also exhibits antitumor activity. TSA is a pan-HDAC inhibitor efficient in nanomolar concentrations $(30,31)$ that induces cell cycle arrest and apoptosis in several cell lines, suggesting its potency to be used as an anticancer drug (32).

The combined effects of VPA and TSA with DNA-damaging drugs (cisplatin and etoposide) on UKF-NB-4 neuroblastoma cells were evaluated using the pro-apoptotic effects of these drugs and apoptosis-involved mechanisms underlying the anticancer activity of these drugs. In addition, we also examined the effects of the combination of the HDAC inhibitors with vicristine, the drug that is used to treat neuroblastomas (1), but acts via a different mechanism of anticancer action. The results found in this report suggest that integrating VPA into the DNA-damaging conventional chemotherapy of high-risk neuroblastoma may improve treatment efficacy.

\section{Materials and methods}

Cell cultures and chemicals. The UKF-NB-4 cell line, established from bone marrow metastases of recurrent high-risk neuroblastoma, was a gift of Professor J. Cinatl Jr (J.W. Goethe University, Frankfurt, Germany). Valproic acid sodium salt (VPA), valpromide (VPM), trichostatin A (TSA) and etoposide (ETO) were purchased from Sigma Chemical Co. (St. Louis, MO, USA). Vincristine (VCR) sulfate was from Teva Pharmaceuticals, Prague, Czech Republic and cisplatin was Platadiam 50 from PLIVA-Lachema, Brno, Czech Republic. All other chemicals used in experiments were of analytical purity or better. Cells were grown at $37^{\circ} \mathrm{C}$ and $5 \% \mathrm{CO}_{2}$, cultivated in Iscove's modified Dulbecco's medium (IMDM) with $10 \%$ fetal bovine serum (both Life Technologies, Carlsbad,
CA, USA). The cells were cultivated for at least $48 \mathrm{~h}$ with tested drugs, because this time period essentially corresponds to the time for two cycles of cell division. Moreover, such a time period is sufficient for the drugs used in this study to enter the tested cells, affect cell cycle and trigger apoptosis (17-20,33,34).

Annexin V/propidium iodide double staining assay. For detection of apoptosis, Annexin V-FITC Apoptosis Detection kit (Biovision, Milpitas, CA, USA) was used according to the manufacturer's instructions and samples were analyzed using flow cytometry (LSR II, BD, Franklin Lakes, CA, USA). Briefly, 0.8x $10^{6}$ UKF-NB-4 cells were plated in 60-mm dishes and treated with individual drugs (VPA dissolved in an IMDM medium), TSA and VPM (dissolved in dimethyl sulfoxide, DMSO), water solution of cisplatin prepared according to the manufacturer's instructions (PLIVA-Lachema, Brno, Czech Republic), etoposide (dissolved in a small volume of DMSO; final volume of DMSO did not exceed $0.5 \%$ ), vincristine sulfate (Teva Czech Industries, Prague, Czech Republic) or their combinations. After exposure to these compounds for $48 \mathrm{~h}$, cells were washed with cold PBS, trypsinized and collected by centrifugation; cells were further re-suspended in $100 \mu \mathrm{l}$ of Annexin binding buffer containing $5 \mu \mathrm{l}$ of FITC Annexin V and $5 \mu \mathrm{l}$ of PI. Then cells were gently vortexed and incubated for $20 \mathrm{~min}$ at room temperature in the dark. Binding buffer $(400 \mu \mathrm{l})$ was added to each tube and centrifuged. Pellets of cells re-suspended in this buffer were then collected and measured using an LSR II flow cytometer (BD) and analyzed with FlowLogic software.

Detection of active caspase-3. To detect cells with active caspase-3, $0.8 \times 10^{6}$ neuroblastoma UKF-NB-4 cells were plated in $60-\mathrm{mm}$ dishes and treated with individual drugs or their combinations for $48 \mathrm{~h}$. Percentage of active caspase3 -positive cells was detected using the CaspGLOW ${ }^{\text {тм }}$ Flourescein Active Caspase-3 Staining kit (eBioscience, San Diego, CA, USA). The procedure used was as described in the manufacturer's instructions and samples were analyzed using flow cytometry (LSR II, BD, Franklin Lakes, CA, USA). Briefly, after exposure to the compounds, control or treated cells were washed with cold PBS, trypsinized and collected by centrifugation. Cell pellets were washed with PBS and after spinning re-suspended in $300 \mu \mathrm{l}$ of a complete medium containing $1 \mu \mathrm{l}$ of FITC labeled DEVD-FMK. Then the cells were incubated for $30 \mathrm{~min}$ at $37^{\circ} \mathrm{C}$ and $5 \% \mathrm{CO}_{2}$. Cells were collected by spinning and pellet was washed with wash buffer (according to the manufacturer's instructions). Re-suspended washed cells were measured using the LSR II flow cytometer (BD, Franklin Lakes, CA, USA) and analyzed with FlowLogic software.

Real-time monitoring of cell viability. The xCELLigence RTCA DP Instrument (ACEA Bioscience Inc., San Diego, CA, USA) placed in a humidified incubator at $37^{\circ} \mathrm{C}$ and $5 \% \mathrm{CO}_{2}$ was used for real-time label-free monitoring of cell-viability (37). UKF-NB-4 cell line (20,000 cells) were seeded into 16-well plates for impedance-based detection. Each condition (control, $1 \mathrm{mM} \mathrm{VPA}, 4 \mu \mathrm{M}$ cisplatin and combination of $1 \mathrm{mM}$ VPA with $4 \mu \mathrm{M}$ cisplatin) was tested in duplicate. Cell index 
(CI) was monitored every $30 \mathrm{~min}$ for $140 \mathrm{~h}$ and data recorded by the supplied RTCA software.

Estimation of contents of acetylated histones $\mathrm{H3}$ and H4. To estimate an acetylation status of histones $\mathrm{H} 3$ and $\mathrm{H} 4,4 \times 10^{6}$ cells were plated in 100-mm dishes and cultivated and treated with tested drugs. Namely, cells were treated with $1 \mathrm{mM}$ VPA, 40 or $150 \mathrm{nM}$ TSA, or $4 \mathrm{mM}$ VPM for $8 \mathrm{~h}$ or with $20 \mu \mathrm{M}$ cisplatin or $8 \mu \mathrm{M}$ etoposide for $24 \mathrm{~h}$. Cells were also treated with cisplatin and etoposide in a combination with $1 \mathrm{mM}$ VPA in two different regimens: i) cells were incubated with cisplatin or etoposide for $24 \mathrm{~h}$ prior to incubation with VPA for $8 \mathrm{~h}$ and ii) cells were incubated with VPA for $8 \mathrm{~h}$ prior to incubation with cisplatin or etoposide for $24 \mathrm{~h}$. Cells were harvested and histones were isolated from the cell pellets. The acid extraction followed by precipitation of histones using trichloracetic acid (TCA) method described by Shechter et al was used (35). The concentration of proteins was measured using a Lowry method (36) with DC Protein Assay (Bio-Rad, Hercules, CA, USA). Histones (5 $\mu \mathrm{g})$ were electrophoretically separated using 4-20\% TGX precast gels (100 mA). After migration, histones were transferred to a nitrocellulose membrane and incubated with 5\% non-fat milk to block non-specific binding. The membranes were then exposed to specific rabbit polyclonal anti-acetyl-histone $\mathrm{H} 3$ (1:4,000) and anti-acetyl-histone H4 $(1: 1,000)$ antibodies (both from Upstate Biotechnology Inc., Lake Placid, NY, USA) overnight at $4^{\circ} \mathrm{C}$. Membranes were washed and exposed to peroxidase-conjugated anti-IgG secondary antibodies $(1: 2,000)$ and the antigen-antibody complex was visualized by enhanced chemiluminescence detection system according to the manufacturer's instructions (Immun-Star HRP Substrate, Bio-Rad), using X-ray film MEDIX XBU (Foma, Hradec Kralove, Czech Republic). The anti-histone H3 antibody (1:10,000; Millipore, San Diego, CA, USA) was used as a loading control.

Histone H2AX phosphorylation status. To determine phosphorylation of histone $\mathrm{H} 2 \mathrm{AX}, 0.8 \times 10^{6}$ cells were plated in $60-\mathrm{mm}$ dishes and treated with individual drugs or their combinations. After exposure to the compounds, control or treated cells were washed with cold PBS, trypsinized and collected by centrifugation. Cell pellets were washed with PBS and after spinning the cells were fixed in $2 \%$ formaldehyde in PBS for 10 min. After PBS washing, the cells were re-suspended in ice-cold $90 \%$ methanol in PBS and incubated for $60 \mathrm{~min}$ at $-20^{\circ} \mathrm{C}$. Then the cells were washed three times with wash buffer (PBS containing $0.5 \%$ BSA and $0.2 \%$ Triton X-100). Cells were incubated in $50 \mu \mathrm{l}$ of wash buffer containing $5 \mu \mathrm{l}$ of pH2AX antibody [Alexa Fluor ${ }^{\circledR} 647$ anti-H2A.X-Phosphorylated (Ser139), Biolegend, San Diego, $\mathrm{CA}, \mathrm{USA}$ ] for $60 \mathrm{~min}$ at $4^{\circ} \mathrm{C}$. Cells were washed and measured using the LSR II (BD, Franklin Lakes, CA, USA) and analyzed with FlowLogic software.

Statistical analysis. Data are expressed as mean \pm SD. Student's t-test was used when comparing two conditions. P-value $<0.05$ was considered as statistically significant. GraphPad Prism6 software was used for this statistical and graphical processing of data. Two-one-sided-test (TOST) was used to test equivalence, XLSTAT software was used.

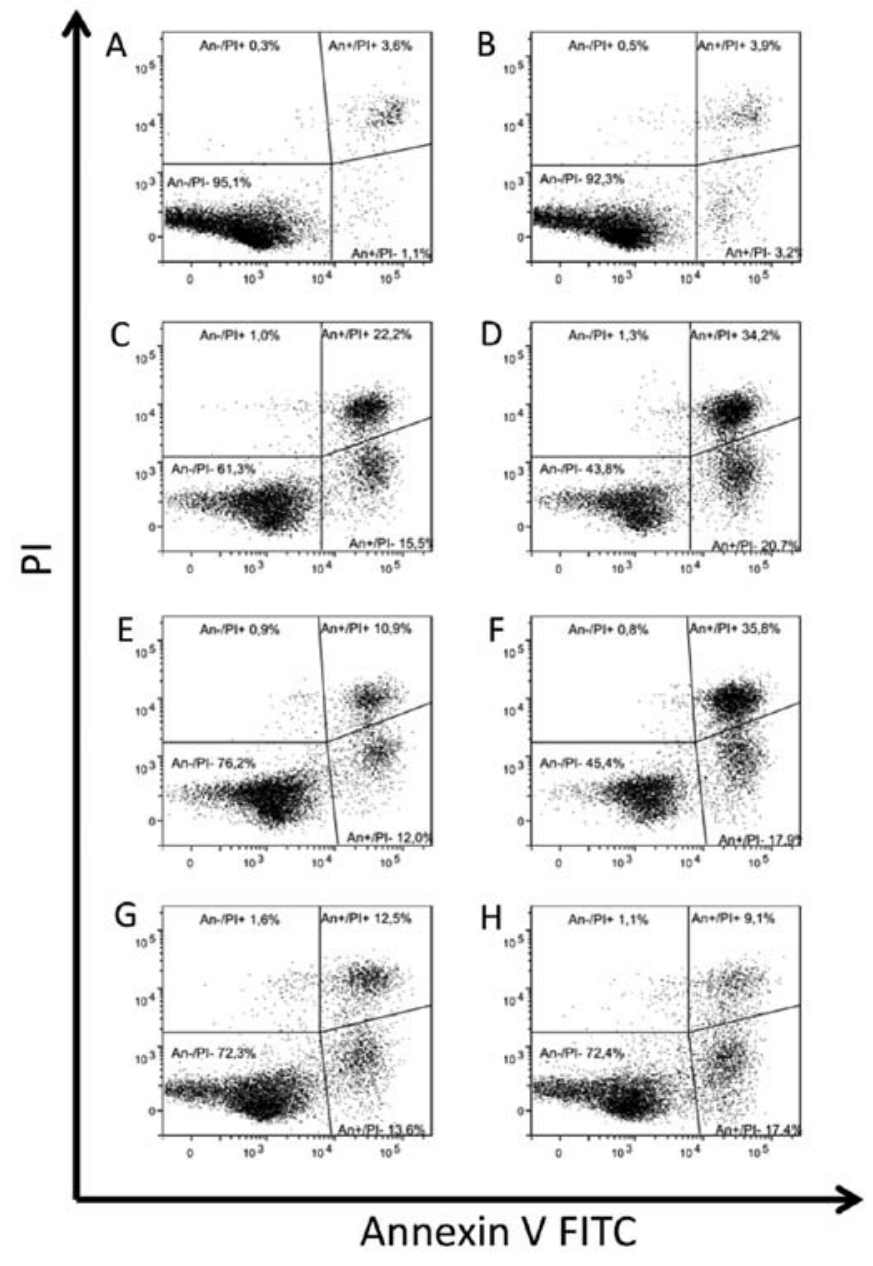

Figure 1. Apoptosis induction in UKF-NB-4 cells by $1 \mathrm{mM}$ VPA (B), $20 \mu \mathrm{M}$ cisplatin (C), $8 \mu \mathrm{M}$ etoposide (E), $20 \mathrm{nM}$ vincristine $(\mathrm{G})$ and their combination with $1 \mathrm{mM}$ VPA [(D) VPA + cisplatin, (F) VPA + etoposide, (H) VPA + vincristine)]. (A) Control cells incubated in a medium without drugs. Apoptosis was measured using Annexin V-FITC/PI labeling. Figure shows representative data from one of three independent experiments.

\section{Results}

VPA synergizes cytotoxicity of cisplatin on UKF-NB-4 human neuroblastoma cells. The first step of this study was to examine the apoptosis induced in UKF-NB-4 cells treated with individual drugs. As translocation of phosphatidylserine to the external membrane leaflet is one of the earliest features of apoptosis, early apoptotic cells can thus be identified by the Annexin V-FITC/PI double staining assay. Besides, double staining with PI allows differentiation of early apoptotic cells with intact membranes (Annexin $\mathrm{V}^{+} / \mathrm{PI}^{-}$) from late apoptotic/ necrotic cells with leaky membranes (Annexin $\mathrm{V}^{+} / \mathrm{PI}^{+}$) and normal cells (Annexin $\mathrm{V}^{-} / \mathrm{PI}^{-}$). As a result, the different groups of these stained cells can be distinguished and quantified by flow cytometry.

As shown in Fig. 1, treatment of UKF-NB-4 neuroblastoma cells with a non-toxic concentration of VPA, $1 \mathrm{mM}$ VPA, for $48 \mathrm{~h}$ does not induce apoptosis in these cells (the amount of Annexin $\mathrm{V}^{-} / \mathrm{PI}^{-}$cells is almost the same as in the control sample, Fig. 1A and B). However, their treatment with cisplatin alone and mainly with this drug simultaneously with 


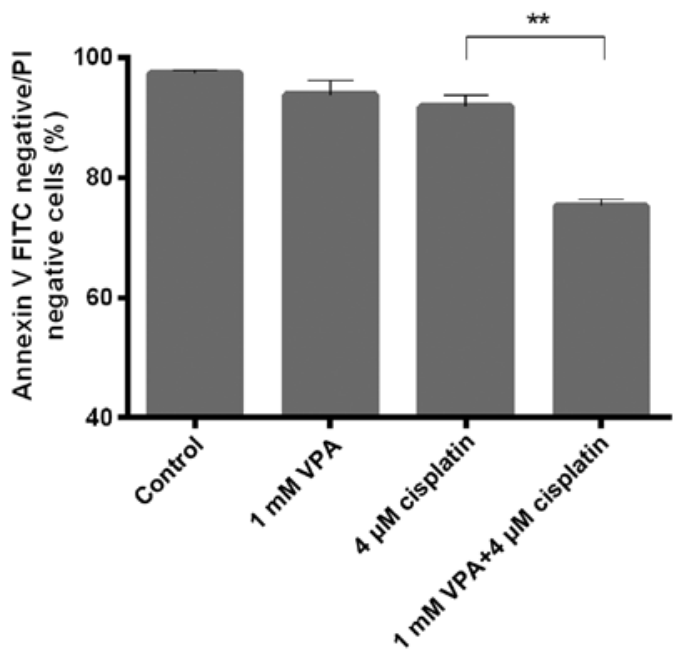

Figure 2. Apoptosis induction in UKF-NB-4 cells by $1 \mathrm{mM}$ VPA, $4 \mu \mathrm{M}$ cisplatin and their combination. Apoptosis was measured using Annexin V-FITC/PI labeling. Mean and SD from three independent experiments is shown. ${ }^{* *} \mathrm{P}<0.01$, a significant difference between cells treated with cisplatin combined with VPA and cisplatin alone (Student's t-test) $(\mathrm{n}=3)$.

VPA resulted in induction of apoptosis (Figs. 1C and D and 2). The Annexin V-FITC/PI double staining assay showed that treatment of UKF-NB-4 cells with $20 \mu \mathrm{M}$ cisplatin for $48 \mathrm{~h}$, decreased the percentage of viable cells to $61.3 \%$ (shown in a lower-left panel in Fig. 1C) with a concomitant increase in percentage of early apoptotic cells to $15.5 \%$ (shown in a lower-right panel in Fig. 1C), and late apoptotic cells to $22.2 \%$ (shown in an upper-right panel in Fig. 1C). These results confirmed that cisplatin plays a critical role in triggering apoptotic cell death in cisplatin-treated UKF-NB-4 cells.

When cells were co-treated with cisplatin and VPA, a higher decrease in the percentage of viable cells than by treatment of cells with cisplatin alone was produced, $\leq 43.8 \%$ (Fig. 1D). This decrease was concomitant with an increase in amounts of early apoptotic cells, to $20.7 \%$ and mainly late apoptotic cells, to $34.2 \%$ (Fig. 1D). These data indicate that VPA elevates a potency of DNA-damaging agent cisplatin to induce apoptosis in UKF-NB-4 cells. Similar trend in induction of apoptosis in UKF-NB-4 cells was also seen after their treatment with $4 \mu \mathrm{M}$ cisplatin (the dose exhibiting a low toxicity to the tested cells, Fig. 2) and by this drug combined with VPA (Fig. 2 for a decrease in the percentage of viable UKF-NB-4 cells caused by cell treatment with cisplatin and VPA).

Caspases, a family of cysteine-aspartic proteases, are known to be crucial mediators in the apoptotic-signaling pathways (38). Since caspase-3 is the major executioner caspase essential for activation of one of the primary apoptotic signaling pathways (39) and its activation ultimately leads to cell death (40), it is thus suited as a read-out in an apoptosis assay. Therefore, in further experiments we evaluated whether apoptosis induced by the above-mentioned treatment regimens is associated with changes in caspase-3 activation. A trend similar to that found using Annexin V, the induction of apoptosis caused by a combined effect of VPA and cisplatin was detected by measuring the percentage of cells with active caspase-3 (Fig. 3). Exposure of UKF-NB-4 cells to $1 \mathrm{mM}$ VPA simultaneously with 4 or $20 \mu \mathrm{M}$
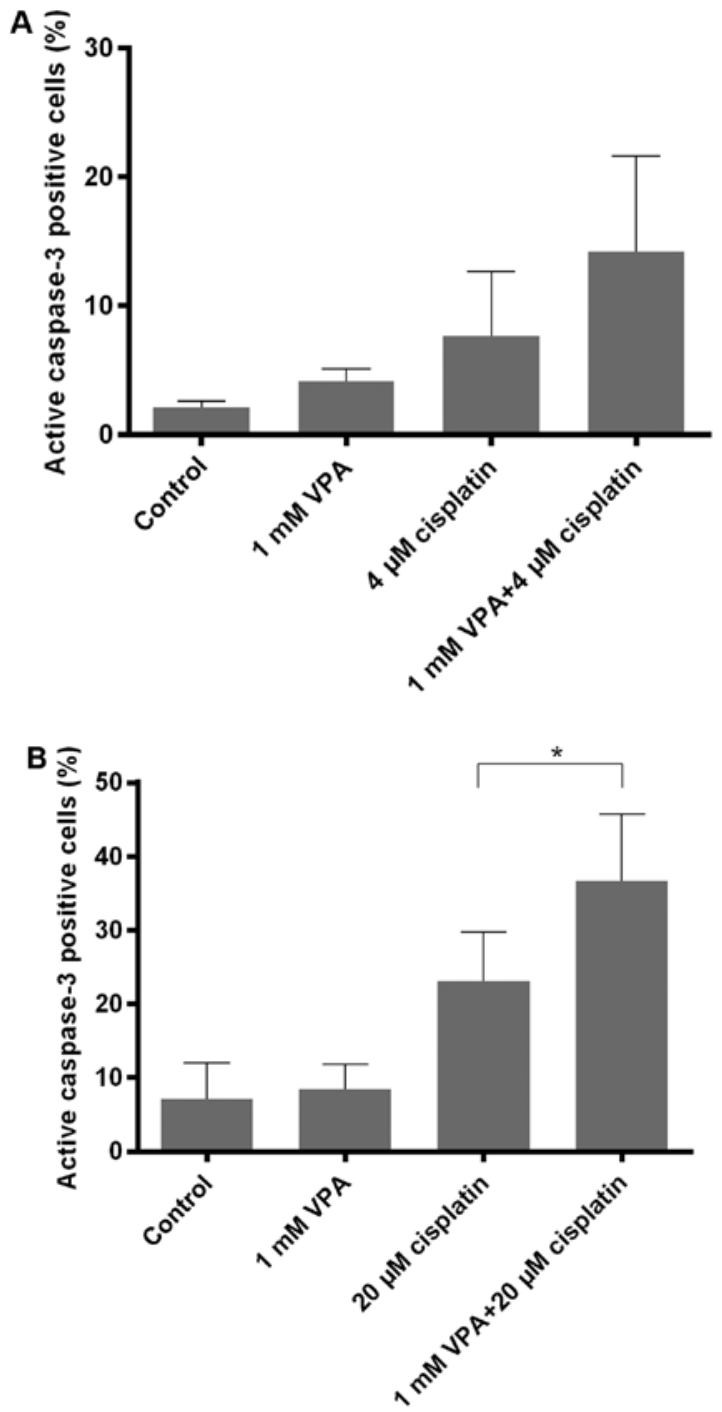

Figure 3. The percentage of UKF-NB-4 cells with active caspase-3 when treated with $1 \mathrm{mM}$ VPA, 4 (A) and $20 \mu \mathrm{M}$ cisplatin (B) and their combination for $48 \mathrm{~h}$. Mean and SD from three independent experiments is shown. ${ }^{*} \mathrm{P}<0.05$, a significant increase in percentage of cells with active caspase- 3 treated with cisplatin combined with VPA, as compared to cells treated with cisplatin alone (Student's t-test) $(n=3)$.

cisplatin increased levels of cells with active caspase-3, by up to 2-times as compared with cells treated with cisplatin alone. These results indicate that apoptosis induced in the UKF-NB-4 neuroblastoma cell line by cisplatin was triggered by the activation of caspase- 3 that is potentiated by co-treatment of the tested cell line with VPA.

An increase in a cytotoxic potency of $4 \mu \mathrm{M}$ cisplatin by $1 \mathrm{mM}$ VPA was also proved by analyzing cell growth with the xCELLigence system (Fig. 4). In this method the relative changes in electrical impedance (expressed as cell index) due to coverage of bottom well by cells, corresponds to cell viability (41). As shown in Fig. 4, the tested cells cultivated with VPA grow slowly up till $\sim 90 \mathrm{~h}$ of cultivation, while their cell index was not increaed after this time period. UKF-NB-4 cells treated with cisplatin grow exponentially till $50 \mathrm{~h}$ of cultivation, but after this time period, cisplatin caused a decrease in their viability. However, after $>100 \mathrm{~h}$ of cultivation, these cells incubated with $4 \mu \mathrm{M}$ cisplatin started to grow 


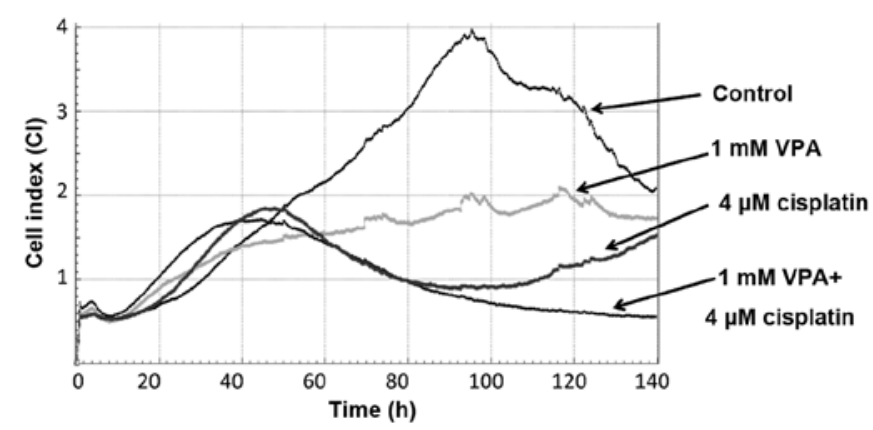

Figure 4. Viability of neuroblastoma UKF-NB-4 cells treated with $1 \mathrm{mM}$ VPA, $4 \mu \mathrm{M}$ cisplatin, or with both drugs. Viability was measured by the xCELLigence system for real-time label-free monitoring of cells and expressed as cell index. Representative data from one of three independent experiments are shown.

again (Fig. 4). Hence, treatment of cells with $4 \mu \mathrm{M}$ cisplatin alone is not sufficient to inhibit cell growth totally; after 90-h treatment, a portion of viable cells were able to grow during further cultivation. The most efficient cytotoxic effect on UKF-NB-4 cells was produced by their co-cultivation with VPA and cisplatin; when this combination was used, the value of cell index decreased close to zero (Fig. 4).

Computation analysis of cell survival calculated by Compusyn software $(42,43)$ was used to estimate whether activities of these two drugs are synergistic. Namely, we calculated the value of the combined effect of VPA and cisplatin and expressed it as combination index (CoI). When the values of CoI are $<0.90$, activities of two drugs are synergistic (the combination index ranging from 0.70 to 0.89 corresponds to a moderate synergism of drugs). However, the values of $\geq 0.9$ indicate that the activities of two drugs are not synergistic $(42,43)$. The value of CoI for the simultaneous effect of $4 \mu \mathrm{M}$ cisplatin and $1 \mathrm{mM}$ VPA equals 0.70 , which corresponds to a moderate synergism of this combination.

Because the effect of the combination of cytostatic drugs with HDAC inhibitors may depend on the treatment regimens, causing either an increase or decrease in cytotoxic effects $(17,20,44)$, we also examined various treatment regimens for a combination of the tested drugs with HDAC inhibitors.

In further experiments, several combinations of treating the UKF-NB-4 cells with VPA and cisplatin were used (Table I). The apoptosis induction in cells cultivated under these treatment regimens is shown in Fig. 5. The most effective drug combination resulting in a decrease in viability of neuroblastoma cells was their exposure to cisplatin and VPA (the cells treated with $20 \mu \mathrm{M}$ cisplatin for $24 \mathrm{~h}$ and then with $1 \mathrm{mM}$ VPA for $48 \mathrm{~h}$ ) (see a combination cisplatin/VPA in Fig. 5). On the contrary, the opposite sequence of drug application (VPA/cisplatin) led to essentially no changes in viability of cells as compared with cultivation of cells with cisplatin alone (see VPA/cisplatin versus 0/cisplatin regimens in Fig. 5). These results demonstrate that VPA can potentiate the toxic effects of cisplatin only if UKF-NB-4 cells are primarily affected by this DNA-damaging drug.

In contrast to VPA, no effects of TSA, another HDAC inhibitor tested in our study, at a non-toxic concentration for UKF-NB-4 (40 nM), on cytotoxicity of cisplatin to UKF-NB-4
Table I. Combination regimens used for treatment of UKF-NB-4 cells with VPA and cisplatin. ${ }^{\mathrm{a}}$

\begin{tabular}{lll}
\hline Designation & \multicolumn{1}{c}{$0-24 \mathrm{~h}$} & \multicolumn{1}{c}{$24-72 \mathrm{~h}$} \\
\hline Control & Medium & Fresh medium \\
Cisplatin/cisplatin & $20 \mu \mathrm{M}$ cisplatin & $20 \mu \mathrm{M}$ cisplatin \\
0/cisplatin & Medium & $1 \mathrm{mM}$ valproate \\
Cisplatin/0 & $20 \mu \mathrm{M}$ cisplatin & Fresh medium \\
Cisplatin/VPA & $20 \mu \mathrm{M}$ cisplatin & $1 \mathrm{mM}$ valproate \\
VPA/0 & $1 \mathrm{mM}$ valproate & Fresh medium \\
0/cisplatin & Medium & $20 \mu \mathrm{M}$ cisplatin \\
VPA/cisplatin & $1 \mathrm{mM}$ valproate & $20 \mu \mathrm{M}$ cisplatin
\end{tabular}

${ }^{\mathrm{a}} 0$ indicates medium cultivation without any drug added.

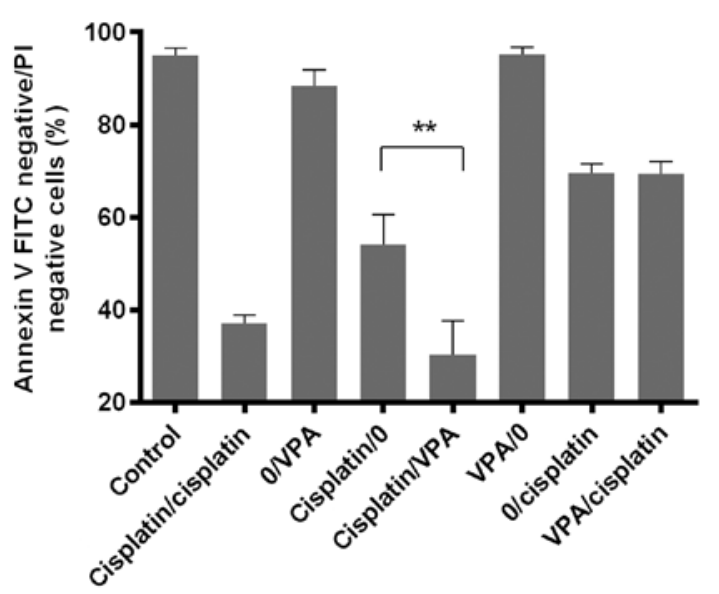

Figure 5. Apoptosis induction in UKF-NB-4 cells by $1 \mathrm{mM} \mathrm{VPA}, 4 \mu \mathrm{M}$ cisplatin and their various combinations. Control, cells treated with a medium without any drug. Experimental conditions for combined treatment of cells are described in Table I. Mean and SD from three independent experiments is shown. ${ }^{* *} \mathrm{P}<0.01$, a significant decrease in viable cells caused by their pretreatment with cisplatin before incubation with VPA as compared to the cells incubated with cisplatin alone (Student's t-test) $(n=3)$.

cells was found using Annexin V-FITC/PI double staining assay or active caspase-3 assay (data not shown).

VPA synergizes cytotoxicity of etoposide on UKF-NB-4 human neuroblastoma cells. The effect of combined treatment of UKF-NB-4 neuroblastoma cells with VPA and etoposide was also investigated. Treatment of these cells with $8 \mu \mathrm{M}$ etoposide, and predominantly with this drug together with $1 \mathrm{mM}$ VPA, resulted in induction of apoptosis (Fig. 1E and F). Treatment of UKF-NB-4 cells with etoposide for $48 \mathrm{~h}$ induced a decrease in the percentage of viable cells to $76.2 \%$ (shown in a lower-left panel in Fig. 1E) with a concomitant increase in percentage of early apoptotic cells, to $12.0 \%$ (shown in a lower-right, panel in Fig. 1E) and late apoptotic cells, to $10.9 \%$ (shown in an upper-right panel in Fig. 1). These findings confirmed the results found in our previous study (20) that etoposide induces apoptotic cell death in UKF-NB-4 cells. 


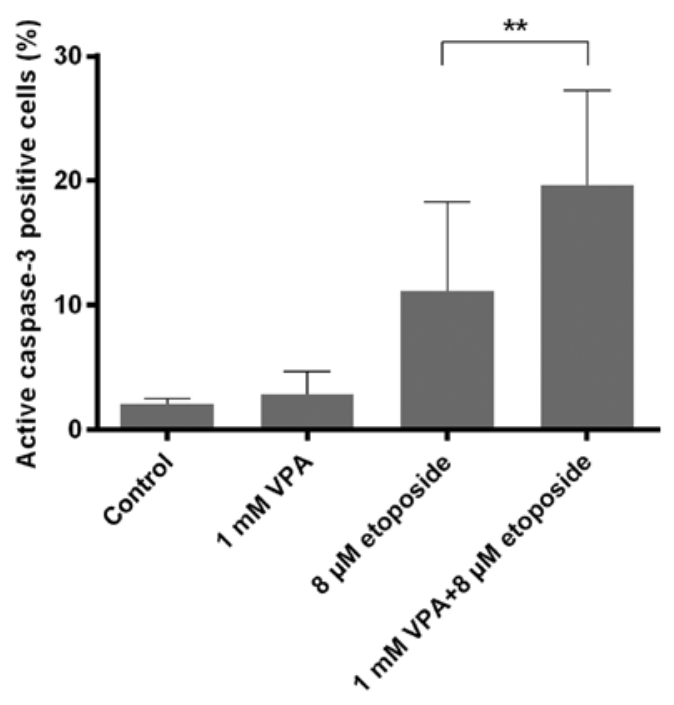

Figure 6. The percentage of UKF-NB-4 cells with active caspase-3 when treated with $1 \mathrm{mM}$ VPA, $8 \mu \mathrm{M}$ etoposide or their combination for $48 \mathrm{~h}$. Mean and $\mathrm{SD}$ from three independent experiments is shown. ${ }^{* *} \mathrm{P}<0.01$, a significant increase in percentage of cells with active caspase- 3 treated with etoposide combined with VPA, as compared to cells incubated with etoposide alone (Student's t-test) $(\mathrm{n}=3)$.

Analogously to exposure of the tested neuroblastoma cells to cisplatin combined with VPA, a 1.7-fold decrease in cell viability (expressed as percentage of Annexin V/PI- cells) was generated in these cells by their exposure to VPA combined with etoposide as compared to their exposure to etoposide alone (Fig. 1E and F). This decrease was parallel with an increase in amounts of early apoptotic cells, to $17.9 \%$, and predominantly late apoptotic cells, to $35.8 \%$ (Fig. 1F). These data indicate that VPA also elevates the potency of the second tested DNA-damaging drug, etoposide, to induce apoptosis in UKF-NB-4 cells.

Using another method testing the effect of combined treatment of UKF-NB-4 cells, measuring the activation of caspase-3, an increase in the etoposide effect by VPA was also found. Exposure of UKF-NB-4 cells to VPA simultaneously with etoposide increased an amount of cells with the active caspase-3, by $\leq 1.7$-times (Fig. 6). All these results indicate the enhanced effect of the combination of these drugs on induction of apoptosis mediated by caspase- 3 activation.

Because several schedules of combined treatment (treatment regimens) of the UKF-NB-4 neuroblastoma cell line with VPA and etoposide have already been carried out in our previous study (20), such experiments were not performed in this study. It should be emphasized that the most effective treatment leading to the highest decrease in viability of neuroblastoma cells was the combined exposure of cells to etoposide followed by their treatment with VPA (cells treated with $8 \mu \mathrm{M}$ etoposide for $24 \mathrm{~h}$ and then with $1 \mathrm{mM}$ VPA for $48 \mathrm{~h})(20)$. Hence, the regimen analogous to that found to be most efficient in treatment of cells with cisplatin combined with VPA. These results demonstrate that VPA can exhibit the potentiation effect only if UKF-NB-4 neuroblastoma cells are primarily influenced either by cisplatin or by etoposide.

Computation analysis $(42,43)$ was again used to estimate whether activities of VPA with etoposide are synergistic. The value of $\mathrm{CoI}$ for the simultaneous effect of $8 \mu \mathrm{M}$ etoposide

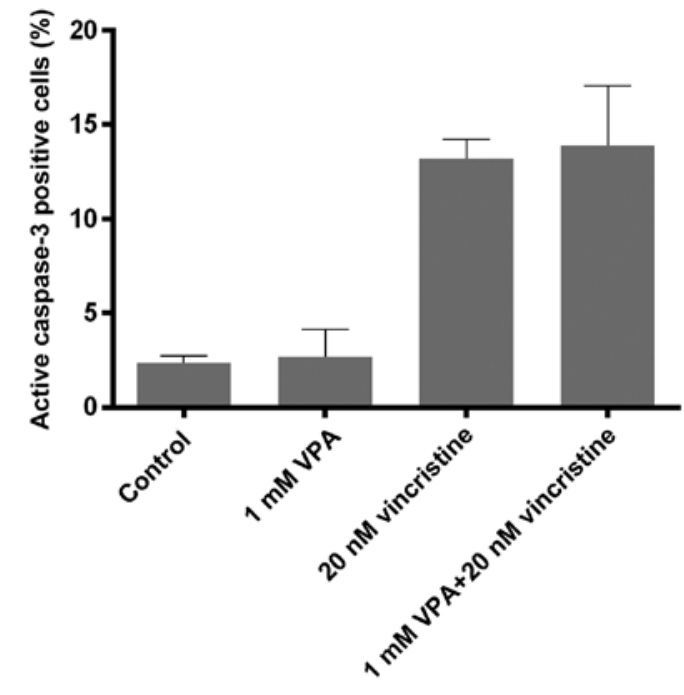

Figure 7. The percentage of UKF-NB-4 cells with active caspase-3 when treated with $1 \mathrm{mM}$ VPA, $20 \mathrm{nM}$ vincristine and their combination for $48 \mathrm{~h}$. Mean and SD from three independent experiments is shown.

and $1 \mathrm{mM}$ VPA equals 0.52 that corresponds to a synergism of these drugs.

When TSA at its non-toxic concentration $(40 \mathrm{nM})$ was used, cytotoxicity of etoposide to UKF-NB-4 cells was essentially not influenced by this HDAC inhibitor (data not shown).

VPA does not potentiate cytotoxicity of a mitotic inhibitor vincristine on UKF-NB-4 humanneuroblastoma cells.In further experiments, the influence of VPA and TSA on cytotoxicity of vincristine, the anticancer drug acting by a mechanism different from that of DNA damage, was investigated. Vincristine is known to induce cell death in tumor cells including neuroblastoma cells by inhibiting the assembly of microtubule structures and disrupting mitosis in the metaphase $(45,46)$.

As shown in Fig. 1, treatment of UKF-NB-4 neuroblastoma cells with $20 \mathrm{nM}$ vincristine led to induction of apoptosis in these cells. The Annexin V-FITC/PI double staining assay indicated that treatment of UKF-NB-4 cells with vincristine for $48 \mathrm{~h}$ induced a decrease in the percentage of viable cells to $72.3 \%$ (shown in a lower-left panel in Fig. 1G), with a concomitant increase in percentage of early apoptotic cells to $13.6 \%$ (shown in a lower-right panel in Fig. 1G), and late apoptotic cells to $12.5 \%$ (shown in an upper-right panel in Fig. 1G). These results confirmed that vincristine is an important drug inducing apoptotic cell death in vincristine-treated UKF-NB-4 cells. However, when the cells were exposed to vincristine combined with VPA, no further changes in cell viability as compared to UKF-NB- 4 cells treated with vincristine were found (Fig. 1H). Likewise, in the case of measuring the activation of caspase-3 in the tested cells treated with vincristine simultaneously with VPA, no increase in a toxic potency of vincristine was found (Fig. 7). These findings demonstrate that the sensitizing effect of VPA on the tested cells is produced only when they are affected by the DNA-damaging drugs (cisplatin and etoposide) before their treatment with this HDAC inhibitor. When TSA at a $40 \mathrm{nM}$ concentration was used, cytotoxicity of vincristine to UKF-NB-4 cells was also not influenced by this HDAC inhibitor (data not shown). 


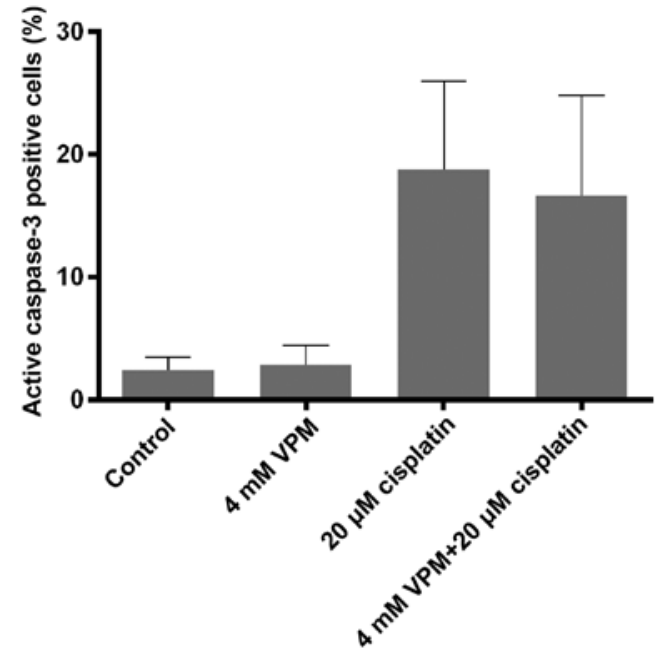

Figure 8 . The percentage of UKF-NB-4 cells with active caspase- 3 when treated with $4 \mathrm{mM}$ VPM, $20 \mu \mathrm{M}$ cisplatin and their combination for $48 \mathrm{~h}$. Mean and SD from three independent experiments is shown.

Treatment of UKF-NB-4 human neuroblastoma cells with valpromide has no effect on cisplatin cytotoxicity. In additional experiments, we investigated cytotoxicity of valpromide (VPM), a derivative of VPA which is also used as an antiepileptic drug, but does not exhibit HDAC inhibition activity (47), on UKF-NB-4 neuroblastoma cells. We evaluated the effect of this drug on induction of apoptosis (measured by Annexin V/PI labeling) in these cells. Treatment of UKF-NB-4 neuroblastoma cells with different concentrations of VPM up to concentrations of $4 \mathrm{mM}$ did not induce apoptosis in these cells (data not shown). When UKF-NB-4 cells were treated with this non-toxic concentration of VPM simultaneously with $20 \mu \mathrm{M}$ cisplatin, no increase in induction of apoptosis caused by cisplatin was produced by VPM (data not shown).

When activation of caspase- 3 in cells treated with VPM together with cisplatin was determined, no increase in the potency of cisplatin to activate caspase-3 by VPM was found (Fig. 8). Exposure of UKF-NB-4 cells to $20 \mu \mathrm{M}$ cisplatin combined with simultaneous treatment with $4 \mathrm{mM}$ VPM does not increase amounts of cells with active caspase-3. These results indicate that the sensitizing effect of VPA on cisplatin toxicity in UKF-NB-4 neuroblastoma cells is related to its HDAC inhibition activity.

Acetylation status of histones $\mathrm{H} 3$ and $\mathrm{H} 4$ in UKF-NB-4 cells treated with VPA, VPM, TSA, cisplatin, etoposide, and cisplatin and etoposide combined with VPA. Acetylation of histones is an important epigenetic phenomenon that is dictated by HDAC activities. Therefore, here we investigated the changes in acetylation of core histones $\mathrm{H} 3$ and $\mathrm{H} 4$ in UKF-NB-4 cells treated with VPA and TSA, as well as with VPM. Cultivation of UKF-NB-4 cells with VPA and TSA at their non-toxic concentrations led to the different effects on acetylation of histones $\mathrm{H} 3$ and $\mathrm{H} 4$. Whereas $1 \mathrm{mM}$ VPA increases acetylation of these histones in UKF-NB-4 cells, confirming its HDAC inhibitory efficiency, a negligible effect of 40 or $50 \mathrm{nM}$ TSA on acetylation of these histones was found (Fig. 9). The concentrations of TSA of 40 or $50 \mathrm{nM}$ are

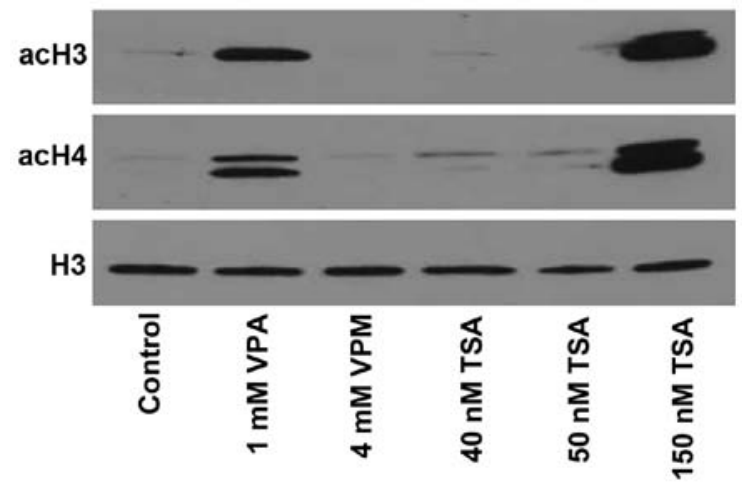

Figure 9. Western blot analysis of acetylated histones $\mathrm{H} 3$ and $\mathrm{H} 4$ in extracts from cells treated with $1 \mathrm{mM}$ VPA, $4 \mathrm{mM}$ VPM, 40, 50 and $150 \mathrm{nM}$ TSA for $8 \mathrm{~h}$ (H3 was used as loading control).

therefore insufficient to inhibit HDAC activities in UKF-NB-4 cells. However, when these cells were cultivated in a medium containing a higher (toxic) concentration of TSA (150 nM), a pronounced increase in acetylation of histones $\mathrm{H} 3$ and $\mathrm{H} 4$ was detected. In contrast to these results, no increase in acetylation of these histones was caused by VPM (Fig. 9). This confirms the absence of HDAC inhibitory effects of this derivative of VPA.

When UKF-NB-4 neuroblastoma cells were treated with cisplatin or etoposide, a low decrease in acetylation of histone $\mathrm{H} 3$ and essentially no effect on acetylation of histone $\mathrm{H} 4$ were found (Fig. 10). In further experiments, two combination treatment regimens of the cells with VPA and cisplatin or VPA with etoposide were used to investigate the effects of combined treatment on the histones $\mathrm{H} 3$ and $\mathrm{H} 4$ acetylation status. Only the regimen, where UKF-NB-4 cells were pretreated with cisplatin or etoposide and then treated with VPA produced an increase in acetylation of histones $\mathrm{H} 3$ and H4 (Fig. 10). This increase in histone acetylation paralleled the potentiation of toxic effects of cisplatin (Fig. 5) or etoposide (20). Hence, only if UKF-NB-4 cells were primarily affected by the tested DNA-damaging drugs prior to cultivation with VPA, this HDAC inhibitor increases acetylation of histones (Fig. 10) and potentiated cytotoxicity of both DNA-damaging drugs on UKF-NB-4 cells (Fig. 1).

VPA does not influence etoposide-mediated phosphorylation of histone $H 2 A X$. Etoposide is known to be the DNA-damaging drug that acts, beside its intercalation into DNA, as an inhibitor of topoisomerase II activity that leads to formation of double-strand breaks in DNA (26-28). Therefore, we examined the effect of VPA on this mechanism of etoposidemediated cytotoxic action. Phosphorylation of histone H2A on serine 139 , termed $\gamma \mathrm{H} 2 \mathrm{AX}(\mathrm{pH} 2 \mathrm{AX})$, by kinases sensing the double-strand DNA break is a sensitive marker of this type of DNA damage (48-51). Therefore, the levels of $\mathrm{pH} 2 \mathrm{AX}$ were determined to analyze whether treatment of cells with etoposide is influenced by VPA. After 48-h cultivation of cells in a medium containing $1 \mathrm{mM} \mathrm{VPA}, 4 \mu \mathrm{M}$ etoposide or their combination, the levels of $\mathrm{pH} 2 \mathrm{AX}$ were examined by flow cytometry. Representative histograms of $\mathrm{pH} 2 \mathrm{AX}$ fluorescence found in these experiments are shown in Fig. 11. 

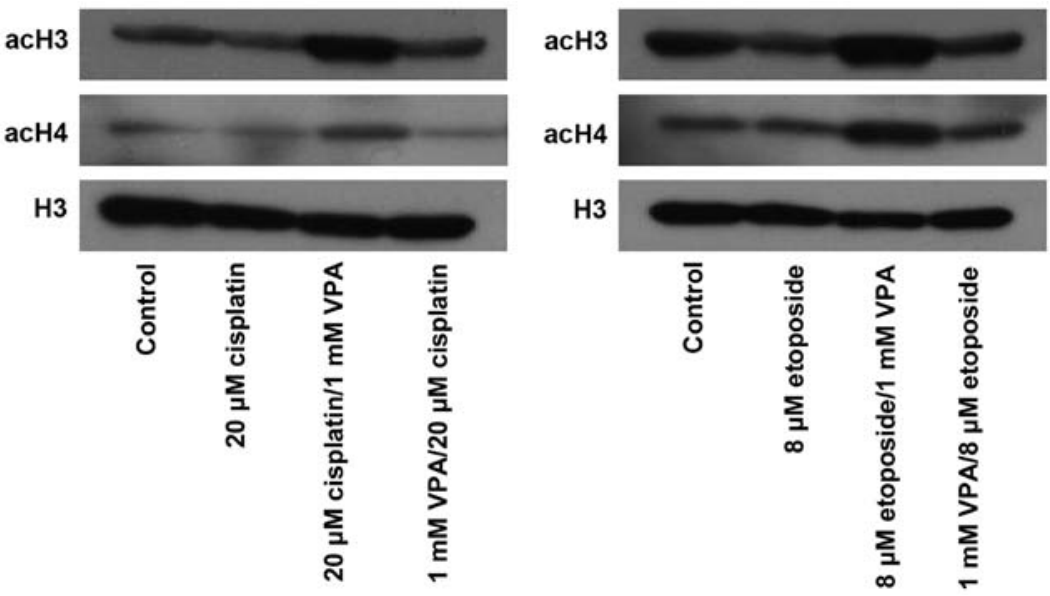

Figure 10. Levels of acetylated histones $\mathrm{H} 3$ and $\mathrm{H} 4$ in extracts from cells treated with $20 \mu \mathrm{M}$ cisplatin and $8 \mu \mathrm{M}$ etoposide, and these drugs combined with $1 \mathrm{mM}$ VPA under different regimens, analyzed by western blotting (H3 was used as loading control).

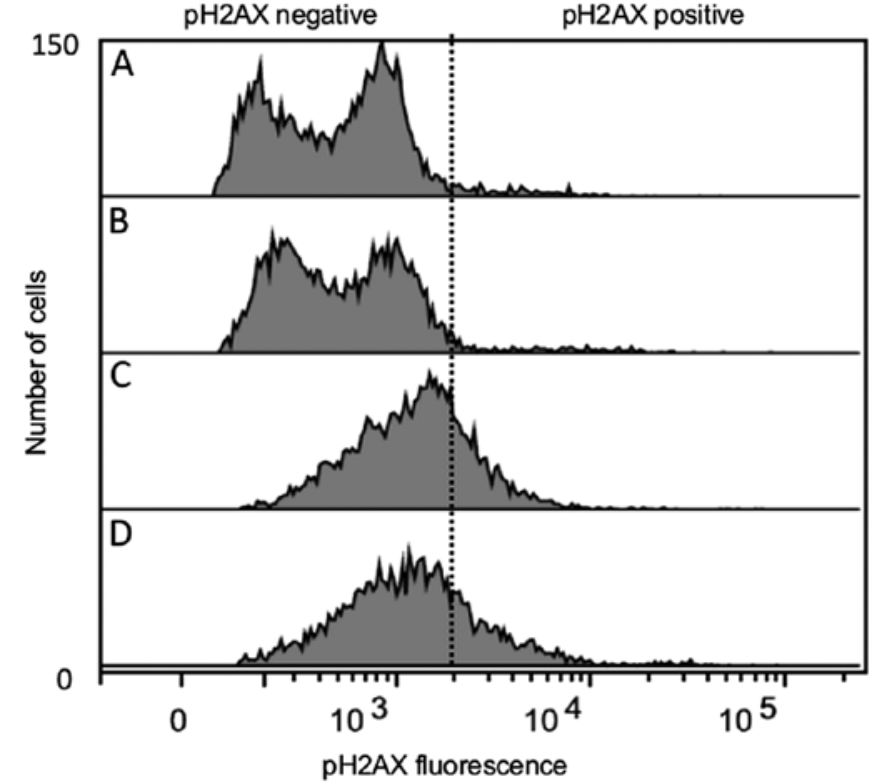

Figure 11. The effects of $1 \mathrm{mM}$ VPA (B), $4 \mu \mathrm{M}$ etoposide (C) or their combination (D) on generation of $\mathrm{pH} 2 \mathrm{AX}$ in UKF-NB-4 cells treated with these drugs for $48 \mathrm{~h}$. (A) Control cells that were incubated without any drug. Representative histogram of $\mathrm{pH} 2 \mathrm{AX}$ fluorescence as a marker of double strand breaks is shown.

Whereas essentially no increase in $\mathrm{pH} 2 \mathrm{AX}$ was induced by VPA (Fig. 11B), a pronounced enhancement in pH2AX was caused by cell exposure to etoposide (Fig. 11C). Co-cultivation of UKF-NB-4 cells with etoposide and VPA (Fig. 11D) did not change percentage of $\mathrm{pH} 2 \mathrm{AX}$-positive cells as compared with cultivation of UKF-NB-4 cell with etoposide alone (Fig. 11C and D).

\section{Discussion}

The poor response of high-risk neuroblastomas to current treatment regimens suggests that novel therapeutic strategies should be developed. The inhibitors of HDACs, used either individually or in the combination with other drugs, were found to be promising anticancer regimens efficient against several cancer cells including neuroblastomas (reviewed in refs. 10,15,17-21).

The results found in this study demonstrate that VPA used at the clinically relevant dose $(1 \mathrm{mM})$ has potentiating effect on cytotoxicity and caspase-3-mediated induction of apoptosis caused by the tested DNA-damaging drugs cisplatin and etoposide. Analyzing the combination index, VPA combined with cisplatin or etoposide was found to act synergistically. However, no sensitizing effect due to VPA was produced with the mitotic inhibitor vincristine. These results indicate that HDAC inhibitor-mediated capability of increasing cytotoxic efficiency of anticancer drugs is connected with the drugs that target cellular DNA. These findings correspond to the results found in the study of dos Santos et al (52) that also investigated the effect of a combination of etoposide or vincristine with the HDAC inhibitor (sodium butyrate, an HDAC inhibitor of the same group as VPA) on human lymphoblastic T-cells. The authors demonstrated that from these two drugs, only etoposide, but not vincristine, was sensitized by the used HDAC inhibitor (52). In their study, the sensitizing effect of the HDAC inhibitor on doxorubicin, another DNA-damaging drug, was also proved (52).

The mechanisms of the potentiating effects of HDAC inhibitors on the efficiency of DNA-damaging drugs have not yet been fully elucidated. It was suggested that HDAC inhibitors promote increased lysine acetylation in nucleosomal histones and are thought to relax chromatin, thereby allowing increased access of transcription factors and DNA-damaging agents to DNA (reviewed in refs. 10,15). In our study, the increased toxicity of cisplatin and etoposide was indeed dependent on the acetylation status of core histones $\mathrm{H} 3$ and $\mathrm{H} 4$ dictated by HDAC inhibitors. VPA increased amounts of acetylated histones $\mathrm{H} 3$ and $\mathrm{H} 4$ and the elevated levels of these acetylated histones correlated with sensitization of UKF-NB-4 cells to cisplatin and etoposide. TSA, another HDAC inhibitor, at a concentration that essentially did not influence acetylation of these histones $(40 \mathrm{nM})$, was ineffective. Likewise, VPM, a structural analogue of VPA, which however does not increase acetylation of histones 
H3 and H4 (Fig. 9), did not enhance cytotoxicity of the tested DNA-damaging drugs (Fig. 8).

It should be, however, emphasized that a sequence of drug application is the crucial feature for sensitizing neuroblastoma cells to cisplatin and etoposide by VPA and the degree of acetylation of histones H3 and H4. Namely, this HDAC inhibitor potentiated the cytotoxic effect of cisplatin or etoposide and acetylation of histones only when added simultaneously, or when cells were preincubated with cisplatin or etoposide before their cultivation with VPA. Only these regimens were appropriate to suppress viability of neuroblastoma cells and to increase acetylation of histones. In contrast, the reversed sequence (pretreatment of cells with VPA before treatment with cisplatin or etoposide) did not give any further increase in cytotoxicity of the DNA-damaging drugs and acetylation of histones. All these findings suggest that DNA damage is crucial for the additional effects of VPA, arguing against the hypothesis based on relaxed chromatin that increases accessibility of DNA-damaging drugs to DNA $(10,15)$. Similarly, the results found by Luchenko et al (44) indicated that DNA relaxation is not required for the synergy of two HDAC inhibitors they tested, belinostat and romidepsin, with cisplatin and etoposide. One can speculate that the changes in the structure of DNA caused by cisplatin and etoposide [i.e., formation of DNA adducts or DNA cross-links by cisplatin, intercalation of etoposide into DNA, and/or formation of reactive oxygen species by both drugs (44,53-56)] increase accessibility of nucleosomal core histones to their acetylation, which additionally determines transcription of some genes involved in DNA repair or apoptosis. This suggestion needs, however, to be further investigated.

Despite the observed synergy of the combination where UKF-NB-4 cells were initially treated with etoposide before VPA in cell survival and apoptosis (20), we found no evidence for enhancement of etoposide-mediated $\mathrm{H} 2 \mathrm{AX}$ phosphorylation when etoposide was combined with VPA (Fig. 11). Doublestrand DNA breaks markedly increased in UKF-NB-4 cells treated with etoposide, but after simultaneous treatment of these cells with etoposide and VPA no further increase in the $\mathrm{pH} 2 \mathrm{AX}$ foci formation was detected. Therefore, instead of inhibition of topoisomerase-II activity by etoposide, leading to formation of double-strand-breaks in DNA, the changes in the structure of DNA mediated by intercalation of etoposide into DNA seem to be responsible for the results found in UKF-NB-4 cells.

One of the challenges in conducting a clinical trial when combining an inhibitor of HDACs VPA with DNA damaging agents will be to achieve optimal DNA damage in a given tumor tissue. The results found in the present study demonstrate that treatment of cells with VPA potentiates the cytotoxicity of DNA damaging agents, cisplatin and etoposide, on UKF-NB-4 cells without increasing their access to DNA. The data presented here show that treatment with cisplatin or etoposide prior to addition of VPA is superior to alternative schedules and supports the development of clinical trials using these combinations for neuroblastoma cells. The clinical use of such combined treatment utilizing DNA-damaging drugs with this HDAC inhibitor could reduce frequent problems, such as dose reductions and temporary discontinuation of treatment as a result of toxicity, and thus could improve the treatment itself and the patient's quality of life.

\section{Acknowledgements}

This study was supported by the GACR (grant 14-8344S), the Charles University in Prague (grants GAUK 635712/2012, GAUK 620612/2012, UNCE 204025/2012) and by $\mathrm{MH}$ CZ-DRO, University Hospital Motol, Prague, Czech Republic 00064203 .

\section{References}

1. Brodeur GM: Neuroblastoma: Biological insights into a clinical enigma. Nat Rev Cancer 3: 203-216, 2003.

2. Schwab M, Westermann F, Hero B and Berthold F: Neuroblastoma: Biology and molecular and chromosomal pathology. Lancet Oncol 4: 472-480, 2003

3. Maris JM, Hogarty MD, Bagatell R and Cohn SL: Neuroblastoma. Lancet 369: 2106-2120, 2007.

4. Furchert SE, Lanvers-Kaminsky C, Juürgens H, Jung M, Loidl A and Frühwald MC: Inhibitors of histone deacetylases as potential therapeutic tools for high-risk embryonal tumors of the nervous system of childhood. Int J Cancer 120: 1787-1794, 2007.

5. Decock A, Ongenaert M, Vandesompele J and Speleman F: Neuroblastoma epigenetics: From candidate gene approaches to genome-wide screenings. Epigenetics 6: 962-970, 2011.

6. Santini V, Gozzini A and Ferrari G: Histone deacetylase inhibitors: Molecular and biological activity as a premise to clinical application. Curr Drug Metab 8: 383-393, 2007.

7. Portela A and Esteller M: Epigenetic modifications and human disease. Nat Biotechnol 28: 1057-1068, 2010.

8. Kouzarides T: Chromatin modifications and their function. Cell 128: 693-705, 2007.

9. Glozak MA, Sengupta N, Zhang X and Seto E: Acetylation and deacetylation of non-histone proteins. Gene 363: 15-23, 2005

10. Stiborová M, Eckschlager T, Poljaková J, Hraběta J, Adam V, Kizek R and Frei E: The synergistic effects of DNA-targeted chemotherapeutics and histone deacetylase inhibitors as therapeutic strategies for cancer treatment. Curr Med Chem 19: 4218-4238, 2012

11. Atmaca A, Al-Batran SE, Maurer A, Neumann A, Heinzel T, Hentsch B, Schwarz SE, Hövelmann S, Göttlicher M, Knuth A, et al: Valproic acid (VPA) in patients with refractory advanced cancer: a dose escalating phase I clinical trial. Br J Cancer 97: 177-182, 2007.

12. Munster P, Marchion D, Bicaku E, Lacevic M, Kim J, Centeno B, Daud A, Neuger A, Minton S and Sullivan D: Clinical and biological effects of valproic acid as a histone deacetylase inhibitor on tumor and surrogate tissues: Phase I/II trial of valproic acid and epirubicin/FEC. Clin Cancer Res 15: 2488-2496, 2009.

13. Rocca A, Minucci S, Tosti G, Croci D, Contegno F, Ballarini M, Nolè F, Munzone E, Salmaggi A, Goldhirsch A, et al: A phase I-II study of the histone deacetylase inhibitor valproic acid plus chemoimmunotherapy in patients with advanced melanoma. Br J Cancer 100: 28-36, 2009.

14. Vandermeers F, Hubert P, Delvenne P, Mascaux C, Grigoriu B, Burny A, Scherpereel A and Willems L: Valproate, in combination with pemetrexed and cisplatin, provides additional efficacy to the treatment of malignant mesothelioma. Clin Cancer Res 15: 2818-2828, 2009

15. Kim MS, Blake M, Baek JH, Kohlhagen G, Pommier Y and Carrier F: Inhibition of histone deacetylase increases cytotoxicity to anticancer drugs targeting DNA. Cancer Res 63: 7291-7300, 2003.

16. Munshi A, Kurland JF, Nishikawa T, Tanaka T, Hobbs ML, Tucker SL, Ismail S, Stevens C and Meyn RE: Histone deacetylase inhibitors radiosensitize human melanoma cells by suppressing DNA repair activity. Clin Cancer Res 11: 4912-4922, 2005.

17. Das CM, Zage PE, Taylor P, Aguilera D, Wolff JE, Lee D and Gopalakrishnan V: Chromatin remodelling at the topoisomerase II-beta promoter is associated with enhanced sensitivity to etoposide in human neuroblastoma cell lines. Eur J Cancer 46: 2771-2780, 2010.

18. Poljakova J, Hrebackova J, Dvorakova M, Moserova M, Eckschlager T, Hrabeta J, Göttlicherova M, Kopejtkova B, Frei E, Kizek R, et al: Anticancer agent ellipticine combined with histone deacetylase inhibitors, valproic acid and trichostatin A, is an effective DNA damage strategy in human neuroblastoma. Neuro Endocrinol Lett 32 (Suppl 1): 101-116, 2011. 
19. Cipro Š, Hřebačková J, Hraběta J, Poljaková J and Eckschlager T: Valproic acid overcomes hypoxia-induced resistance to apoptosis. Oncol Rep 27: 1219-1226, 2012.

20. Groh T, Hrabeta J, Poljakova J, Eckschlager T and Stiborova M: Impact of histone deacetylase inhibitor valproic acid on the anticancer effect of etoposide on neuroblastoma cells. Neuro Endocrinol Lett 33 (Suppl 3): S16-S24, 2012.

21. Wang G, Edwards H, Caldwell JT, Buck SA, Qing WY, Taub JW, Ge Y and Wang Z: Panobinostat synergistically enhances the cytotoxic effects of cisplatin, doxorubicin or etoposide on high-risk neuroblastoma cells. PLoS One 8: e76662, 2013.

22. Hrabeta J, Stiborova M, Adam V, Kizek R and Eckschlager T: Histone deacetylase inhibitors in cancer therapy. A review. Biomed Pap Med Fac Univ Palacky Olomouc Czech Repub 158 161-169, 2014.

23. Kartalou M and Essigmann JM: Mechanisms of resistance to cisplatin. Mutat Res 478: 23-43, 2001.

24. Miyajima A, Nakashima J, Yoshioka K, Tachibana M, Tazaki H and Murai M: Role of reactive oxygen species in cis-dichlorodiammineplatinum-induced cytotoxicity on bladder cancer cells. Br J Cancer 76: 206-210, 1997.

25. Huang H-L, Fang L-W, Lu S-P, Chou C-K, Luh T-Y and Lai M-Z: DNA-damaging reagents induce apoptosis through reactive oxygen species-dependent Fas aggregation. Oncogene 22: 8168-8177, 2003.

26. Wozniak AJ and Ross WE: DNA damage as a basis for 4'-demethylepipodophyllotoxin-9-(4,6-O-ethylidene-beta-D-glucopyranoside) (etoposide) cytotoxicity. Cancer Res 43: 120-124, 1983.

27. Hande KR: Etoposide: Four decades of development of a topoisomerase II inhibitor. Eur J Cancer 34: 1514-1521, 1998

28. Baldwin EL and Osheroff N: Etoposide, topoisomerase II and cancer. Curr Med Chem Anticancer Agents 5: 363-372, 2005.

29. New M, Olzscha H and La Thangue NB: HDAC inhibitor-based therapies: Can we interpret the code? Mol Oncol 6: 637-656, 2012.

30. Yoshida M, Kijima M, Akita M and Beppu T: Potent and specific inhibition of mammalian histone deacetylase both in vivo and in vitro by trichostatin A. J Biol Chem 265: 17174-17179, 1990.

31. Yoon CY, Park MJ, Lee JS, Lee SC, Oh JJ, Park H, Chung CW, Abdullajanov MM, Jeong SJ, Hong SK, et al: The histone deacetylase inhibitor trichostatin A synergistically resensitizes a cisplatin resistant human bladder cancer cell line. J Urol 185 $1102-1111,2011$

32. Meng J, Zhang H-H, Zhou C-X, Li C, Zhang F and Mei Q-B: The histone deacetylase inhibitor trichostatin A induces cell cycle arrest and apoptosis in colorectal cancer cells via p53-dependent and -independent pathways. Oncol Rep 28: 384-388, 2012.

33. Poljaková J, Eckschlager T, Hraběta J, Hrebacková J, Smutný S, Frei E, Martínek V, Kizek R and Stiborová M: The mechanism of cytotoxicity and DNA adduct formation by the anticancer drug ellipticine in human neuroblastoma cells. Biochem Pharmacol 77: 1466-1479, 2009

34. Poljaková J, Groh T, Gudino ZO, Hraběta J, Bořek-Dohalská L, Kizek R, Doktorová $\mathrm{H}$, Eckschlager $\mathrm{T}$ and Stiborová $\mathrm{M}$ : Hypoxia-mediated histone acetylation and expression of $\mathrm{N}$-myc transcription factor dictate aggressiveness of neuroblastoma cells. Oncol Rep 31: 1928-1934, 2014.

35. Shechter D, Dormann HL, Allis CD and Hake SB: Extraction, purification and analysis of histones. Nat Protoc 2: 1445-1457, 2007.

36. Lowry OH, Rosebrough NJ, Farr AL and Randall RJ: Protein measurement with the Folin phenol reagent. J Biol Chem 193: 265-275, 1951

37. Ke N, Wang X, Xu X and Abassi YA: The xCELLigence system for real-time and label-free monitoring of cell viability. Methods Mol Biol 740: 33-43, 2011.

38. Earnshaw WC, Martins LM and Kaufmann SH: Mammalian caspases: Structure, activation, substrates, and functions during apoptosis. Annu Rev Biochem 68: 383-424, 1999.
39. Porter AG and Jänicke RU: Emerging roles of caspase-3 in apoptosis. Cell Death Differ 6: 99-104, 1999.

40. Slee EA, Adrain C and Martin SJ: Executioner caspase-3, -6, and -7 perform distinct, non-redundant roles during the demolition phase of apoptosis. J Biol Chem 276: 7320-7326, 2001

41. Atienza JM, Yu N, Kirstein SL, Xi B, Wang X, Xu X and Abassi YA: Dynamic and label-free cell-based assays using the real-time cell electronic sensing system. Assay Drug Dev Technol 4: 597-607, 2006.

42. Chou TC and Talalay P: Quantitative analysis of dose-effect relationships: The combined effects of multiple drugs or enzyme inhibitors. Adv Enzyme Regul 22: 27-55, 1984.

43. Chou T-C: Theoretical basis, experimental design, and computerized simulation of synergism and antagonism in drug combination studies. Pharmacol Rev 58: 621-681, 2006.

44. Luchenko VL, Salcido CD, Zhang Y, Agama K, KomlodiPasztor E, Murphy RF, Giaccone G, Pommier Y, Bates SE and Varticovski L: Schedule-dependent synergy of histone deacetylase inhibitors with DNA damaging agents in small cell lung cancer. Cell Cycle 10: 3119-3128, 2011.

45. Jordan MA and Wilson L: Microtubules as a target for anticancer drugs. Nat Rev Cancer 4: 253-265, 2004.

46. Tu Y, Cheng S, Zhang S, Sun $\mathrm{H}$ and $\mathrm{Xu} Z$ Z: Vincristine induces cell cycle arrest and apoptosis in SH-SY5Y human neuroblastoma cells. Int J Mol Med 31: 113-119, 2013.

47. Phiel CJ, Zhang F, Huang EY, Guenther MG, Lazar MA and Klein PS: Histone deacetylase is a direct target of valproic acid, a potent anticonvulsant, mood stabilizer, and teratogen. J Biol Chem 276: 36734-36741, 2001

48. Sokolov MV, Dickey JS, Bonner WM and Sedelnikova OA gamma-H2AX in bystander cells: Not just a radiation-triggered event, a cellular response to stress mediated by intercellular communication. Cell Cycle 6: 2210-2212, 2007.

49. Bonner WM, Redon CE, Dickey JS, Nakamura AJ, Sedelnikova OA, Solier S and Pommier Y: GammaH2AX and cancer. Nat Rev Cancer 8: 957-967, 2008.

50. Nakamura AJ, Rao VA, Pommier Y and Bonner WM: The complexity of phosphorylated $\mathrm{H} 2 \mathrm{AX}$ foci formation and DNA repair assembly at DNA double-strand breaks. Cell Cycle 9: 389-397, 2010.

51. Yuan J, Adamski R and Chen J: Focus on histone variant H2AX: To be or not to be. FEBS Lett 584: 3717-3724, 2010.

52. dos Santos MP, Schwartsmann G, Roesler R, Brunetto AL and Abujamra AL: Sodium butyrate enhances the cytotoxic effect of antineoplastic drugs in human lymphoblastic T-cells. Leuk Res 33: 218-221, 2009.

53. Kurz EU, Wilson SE, Leader KB, Sampey BP, Allan WP, Yalowich JC and Kroll DJ: The histone deacetylase inhibitor sodium butyrate induces DNA topoisomerase II alpha expression and confers hypersensitivity to etoposide in human leukemic cell lines. Mol Cancer Ther 1: 121-131, 2001.

54. Bruzzese F, Rocco M, Castelli S, Di Gennaro E, Desideri A and Budillon A: Synergistic antitumor effect between vorinostat and topotecan in small cell lung cancer cells is mediated by generation of reactive oxygen species and DNA damage-induced apoptosis. Mol Cancer Ther 8: 3075-3087, 2009.

55. Itoh T, Terazawa R, Kojima K, Nakane K, Deguchi T, Ando M, Tsukamasa $\mathrm{Y}$, Ito $\mathrm{M}$ and Nozawa $\mathrm{Y}$ : Cisplatin induces production of reactive oxygen species via NADPH oxidase activation in human prostate cancer cells. Free Radic Res 45: 1033-1039, 2011.

56. Yu C, Friday BB, Lai JP, McCollum A, Atadja P, Roberts LR and Adjei AA: Abrogation of MAPK and Akt signaling by AEE788 synergistically potentiates histone deacetylase inhibitor-induced apoptosis through reactive oxygen species generation. Clin Cancer Res 13: 1140-1148, 2007. 